\title{
ABC5 International Consensus Conference on Advanced Breast Cancer, Lisbon, 16 November 2019
}

Commentary by the German panel of experts on the $A B C 5$ voting results ${ }^{1}$

\section{ABC5 - Internationale Konsensuskonferenz zum fortgeschrittenen Mammakarzinom, Lissabon, 16.11.2019}

Deutsche Expertengruppe kommentiert ABC5-Abstimmungsergebnisse

\section{(ㄷ) (1) (오 $\ominus$}

Authors

Michael Untch ${ }^{1}$, Rachel Würstlein ${ }^{2}$, Diana Lüftner ${ }^{3}$, Renate Haidinger ${ }^{4}$, Peter A. Fasching ${ }^{5}$, Doris Augustin ${ }^{6}$, Susanne Briest ${ }^{7}$, Johannes Ettl ${ }^{8}$, Frank Förster ${ }^{9}$, Christian M. Kurbacher ${ }^{10}$, Hans-Joachim Lück ${ }^{11}$, Norbert Marschner ${ }^{12}$, Lothar Müller ${ }^{13}$, Volkmar Müller ${ }^{14}$, Isabel Radke ${ }^{15}$, Eugen Ruckhäberle ${ }^{16}$, Iris Scheffen ${ }^{17}$, Eva Schumacher-Wulf ${ }^{18}$, Moritz Schwoerer ${ }^{19}$, Dieter Steinfeld-Birg ${ }^{20}$, Katja Ziegler-Löhr ${ }^{21}$, Christoph Thomssen ${ }^{22}$, Nadia Harbeck ${ }^{23}$

\section{Affiliations}

1 Klinik für Gynäkologie und Geburtshilfe, Brustzentrum und Gynäkologisch Onkologisches Zentrum, HELIOS Klinikum Berlin Buch, Berlin, Germany

2 Brustzentrum und Comprehensive Cancer Center (CCC) München, Klinik und Poliklinik für Frauenheilkunde und Geburtshilfe, Universität München (LMU), München, Germany

3 Medizinische Klinik mit Schwerpunkt Hämatologie, Onkologie und Tumorimmunologie, Charité Berlin, Campus Benjamin Franklin, Berlin, Germany

4 Brustkrebs Deutschland e.V.; patient advocate, Germany

5 Universitätsfrauenklinik Erlangen, Comprehensive Cancer Center (CCC) Erlangen-EMN, Friedrich-Alexander Universität Erlangen-Nürnberg, Erlangen, Germany

6 Mammazentrum Ostbayern, DONAUISAR Klinikum Deggendorf, Deggendorf, Germany

7 Klinik und Poliklinik für Frauenheilkunde, Universitätsklinikum Leipzig, Leipzig, Germany

8 Frauenklinik und Poliklinik für Frauenheilkunde und Geburtshilfe, Klinikum rechts der Isar, München, Germany

9 Praxis für Gynäkologie und Geburtshilfe, Gynäkologische Onkologie und Palliativmedizin, Poliklinik gGmbH, Chemnitz, Germany

10 Gynäkologie I (Gynäkologische Onkologie), Gynäkologisches Zentrum, Bonn-Friedensplatz, Bonn, Germany

11 Schwerpunktpraxis für Hämato-Onkologie, Hannover, Germany

12 Gemeinschaftspraxis für interdisziplinäre Onkologie und Hämatologie, Freiburg, Germany

13 Onkologische Schwerpunktpraxis Leer-Emden-Papenburg, Leer, Emden, Papenburg, Germany

14 Universitätsfrauenklinik Hamburg-Eppendorf, Hamburg, Germany

15 Brustzentrum, Universitätsklinikum Münster, Münster, Germany
16 Frauenklinik, der Heinrich-Heine-Universität, Düsseldorf, Germany

17 Brustzentrum am St. Elisabeth-Krankenhaus GmbH, Köln, Germany

18 Mamma Mia! Brustkrebs-Magazin, Kronberg, Germany

19 Frauenklinik, Klinikum Fürstenfeldbruck, Fürstenfeldbruck, Germany

20 Gynäkologische Onkologie Augsburg, Augsburg, Germany

21 Schwerpunktpraxis für gynäkologische Onkologie, Köln, Köln, Germany

22 Universitätsklinik und Poliklinik für Gynäkologie, MartinLuther-Universität, Halle an der Saale; $A B C$ panel member, $A B C$ scientific committee member, Germany

23 Brustzentrum und Comprehensive Cancer Center (CCC) München, Universität München (LMU), München; $A B C$ panel member, Germany

Key words

ABC5 consensus, advanced breast cancer, precision medicine, 2019 study data

Schlüsselwörter

ABC5-Konsensus, fortgeschrittenes Mammakarzinom, Präzisionsmedizin, Studiendaten 2019

received 12.3.2020

accepted 16.3.2020

1 The commentary by the German panel of experts is based on the voting results of the $A B C 5$ panelists who attended the conference in Lisbon. This paper represents the opinion and perspective of German breast cancer specialists. The official $A B C 5$ consensus will be published elsewhere under the authorship of the $A B C 5$ panelists. 
Bibliography

DOI https://doi.org/10.1055/a-1139-9380

Geburtsh Frauenheilk 2020; 80: 588-600 @ Georg Thieme

Verlag KG Stuttgart · New York | ISSN 0016-5751

\section{Correspondence}

Prof. Dr. med. Michael Untch

Klinik für Gynäkologie und Geburtshilfe, Brustzentrum und Gynäkologisch Onkologisches Zentrum, HELIOS Klinikum

Berlin Buch, Berlin

Schwanebecker Chaussee 50, 13125 Berlin, Germany

michael.untch@helios-gesundheit.de

$\theta$

Deutsche Version unter:

https://doi.org/10.1055/a-1139-9380

\section{ABSTRACT}

The Advanced Breast Cancer Fifth International Consensus Conference $(A B C 5)$ which focuses on the diagnosis and treatment of advanced breast cancer was held in Lisbon on November 14-16, 2019. The aim of the conference is to standardize the treatment of advanced breast cancer worldwide using evidence-based data and to ensure that patients with advanced breast disease anywhere in the world are treated appropriately and have access to the latest therapies. This year, the emphasis was on new developments and study results from patients with advanced breast cancer as well as precision medicine. The collaboration with patient advocates from all over the globe is also an important goal of the $A B C$ Conference, which is why the international $A B C$ panel also included a number of patient advocates. We present a commentary on the voting results of the $A B C 5$ panelists in Lisbon by a working group of German breast cancer specialists together with the implications for routine clinical care in Germany. The commentary is based on the recommendations of the Breast Commission of the German Gynecological Oncology Working Group (AGO). This commentary is useful, it includes country-specific features for the $A B C$ consensus.

\section{ZUSAMMENFASSUNG}

Vom 14. bis 16. November 2019 fand in Lissabon die fünfte internationale Konsensuskonferenz ABC5 (Advanced Breast Cancer Fifth Consensus) zu Diagnostik und Behandlung des fortgeschrittenen Mammakarzinoms statt. Ziel ist es, die Behandlung der Patientinnen mit fortgeschrittenem Mammakarzinom weltweit auf evidenzbasierter Grundlage zu standardisieren und sicherzustellen, dass Patientinnen überall auf der Welt adäquat behandelt werden und Zugang zu neuen Therapien erhalten. Ein inhaltlicher Schwerpunkt lag dieses Jahr auf neuen Entwicklungen und Studienergebnissen beim fortgeschrittenen Mammakarzinom sowie der Präzisionsmedizin. Zudem ist die Zusammenarbeit mit den Patientenvertreterinnen aus aller Welt ein wichtiges Anliegen der ABCKonferenz, weshalb in dem international zusammengesetzten ABC-Panel auch Patientenvertreterinnen sind. Im vorliegenden Manuskript werden die Abstimmungsergebnisse der $A B C 5$-Panelisten vor Ort durch eine Arbeitsgruppe deutscher Brustkrebsexperten für den Therapiealltag in Deutschland kommentiert. Der Kommentierung liegen die Empfehlungen der Arbeitsgemeinschaft gynäkologische Onkologie (AGO), Kommission „Mamma“ zugrunde. Sie erscheint sinnvoll, da in den $A B C-K o n s e n s u s$ auch länderspezifische Besonderheiten einfließen.

\section{Introduction}

The Advanced Breast Cancer Consensus (ABC) Conference on the diagnosis and treatment of advanced breast cancer, an international conference which recently convened for the fifth time (ABC5), was held on November 14-16, 2019 in Lisbon. The goal of the $A B C$ consensus is to achieve international harmonization and standardization of the care of patients with advanced local or metastatic breast cancer. The ABC Conference is organized by the European School of Oncology (ESO) in cooperation with the European Society of Clinical Oncology (ESMO).

The consensus is developed by an international interdisciplinary group of experts. This year's ABC5 consensus panel (see box) consisted of 44 breast cancer specialists and included four patient advocates, a specialist oncology nurse and a psycho-oncologist. Breast cancer specialists from Germany on the panel included Prof. Nadia Harbeck (Munich) and Prof. Christoph Thomssen (Halle/Saale) as well as Renate Haidinger, the first patient advocate from Germany to sit on the panel. Prof. Thomssen was also a member of the 4-member scientific committee of the ABC5 Conference.

\author{
ABC5 PANELISTS \\ 1. Fatima Cardoso, PT (coordinating chair) \\ 2. Eric P. Winer, US (chair) \\ 3. Alberto Costa, $\mathrm{CH} / \mathrm{IT}$ (chair) \\ 4. Larry Norton, US (chair) \\ 5. Giuseppe Curigliano, IT (co-chair, ESMO) \\ 6. Shirley A. Metz, US (co-chair, patient advocate) \\ 7. Karen Gelmon, CA (scientific committee) \\ 8. Frédérique Penault-Llorca, FR (scientific committee) \\ 9. Elzbieta Senkus, PL (scientific committee) \\ 10. Christoph Thomssen, DE (scientific committee) \\ 11. Mona Elzayat, AT (patient advocate) \\ 12. Renate Haidinger, DE (patient advocate) \\ 13. Ranjit Kaur, MY (patient advocate) \\ 14. Theresa Wiseman, UK (nurse, EONS) \\ 15. Lesley Fallowfield, UK (psycho-oncologist) \\ 16. Matti S. Aapro, CH \\ 17. Fabrice André, FR \\ 18. Carlos H. Barrios, BR
}


19. Jonas Bergh, SE

20. Gouri S. Bhattacharyya, IN

21. Laura Biganzoli, IT

22. Maria João Cardoso, PT

23. Lisa Carey, US

24. Javier Cortés, ES

25. Nagi El Saghir, LB

26. Alex Eniu, RO

27. Prudence A. Francis, AU

28. Joseph Gligorov, FR

29. Nadia Harbeck, DE

30. Xichun $\mathrm{Hu}, \mathrm{CN}$

31. Bella Kaufman, IL

32. Belinda E. Kiely, AU

33. Sung-Bae Kim, KR

34. Nancy U. Lin, US

35. Silvia Neciosup,PE

36. Birgitte V. Offersen, DK

37. Shinji Ohno, JP

38. Olivia Pagani, $\mathrm{CH}$

39. Shani Paluch-Shimon, IL

40. Aleix Prat, ES

41. Hope S. Rugo, US

42. George W. Sledge, US

43. Daniel A. Vorobiof, US

44. Binghe $\mathrm{Xu}, \mathrm{CN}$

\section{Discussion of the $A B C 5$ consensus from a German perspective}

This "post $A B C 5$ " publication comments on the $A B C 5$ voting results in the context of German treatment recommendations, in particular the annually updated treatment recommendations of the Breast Commission of the Gynecological Oncology Working Group (AGO) [1], and specifies how they can be applied in routine clinical practice in Germany. The German panel of experts refers to the voting results of the $A B C 5$ panelists in Lisbon and not to the final written $A B C 5$ consensus which, as in previous years, will be published in the Annals of Oncology and The Breast $[2,4-6]$.

The focus at the ABC5 Consensus Conference was on the latest developments and most recent study data on the treatment of patients with advanced and metastatic breast cancer. The ABC5 consensus votes in Lisbon referred only to new or modified statements. In those areas where no changes were made to previous content, interested parties are referred to the $A B C 4$ consensus of 2017 and the associated ABC4 consensus guidelines; statements which were not amended continue to be valid [2]. In the following, the German group of experts discuss new statements and the voting results. Those wishing for information on other issues are referred to the post-ABC4 paper which was completed and published after the ABC4 consensus [3].

Panelists could vote on statements presented at the conference by responding with "yes" (agreement), “no" (rejection) or "abstain". The additional voting option "insufficient data" could be used if the data was insufficient to vote either "yes" or "no".
- Table 1 Level of evidence grading system for the ABC5 consensus [49].

\begin{tabular}{|c|c|}
\hline & \\
\hline I & $\begin{array}{l}\text { Evidence from at least one large randomized, } \\
\text { controlled trial of good methodological quality (low } \\
\text { potential for bias) or meta-analyses of validated, well- } \\
\text { conducted, randomized trials without heterogeneity. }\end{array}$ \\
\hline II & $\begin{array}{l}\text { Small randomized trials or large randomized trials } \\
\text { with a suspicion of bias (lower methodological quality) } \\
\text { or meta-analyses of such trials or of trials with demon- } \\
\text { strated heterogeneity. }\end{array}$ \\
\hline III & Prospective cohort studies \\
\hline IV & Retrospective cohort studies or case-control studies \\
\hline V & $\begin{array}{l}\text { Studies without control group, case reports, export } \\
\text { opinions }\end{array}$ \\
\hline & \\
\hline A & $\begin{array}{l}\text { Strong evidence for efficacy with a substantial clinical } \\
\text { benefit, strongly recommended }\end{array}$ \\
\hline B & $\begin{array}{l}\text { Strong or moderate evidence for efficacy but with } \\
\text { a limited clinical benefit, generally recommended }\end{array}$ \\
\hline C & $\begin{array}{l}\text { Insufficient evidence for efficacy or benefit does not } \\
\text { outweigh the risk or the disadvantages of treatment } \\
\text { (adverse effects, costs...), optional }\end{array}$ \\
\hline D & $\begin{array}{l}\text { Moderate evidence against efficacy or for adverse } \\
\text { outcome, generally not recommended }\end{array}$ \\
\hline $\mathrm{E}$ & $\begin{array}{l}\text { Strong evidence against efficacy or for adverse } \\
\text { outcome, never recommended }\end{array}$ \\
\hline
\end{tabular}

The grading system of the $A B C 5$ consensus is based on the treatment guidelines of the ESMO [7] ( $\triangleright$ Table 1$)$.

\section{General Statements and Definitions in the $\mathrm{ABC} 5$ Consensus}

\section{Definition of "visceral crisis"}

A visceral crisis triggers an immediate pressure to treat and requires a different therapeutic approach to that used when treating patients with metastatic breast cancer who are not experiencing a visceral crisis. The $A B C 5$ panelists defined a visceral crisis as severe organ dysfunction accompanied by significant symptoms and rapid progression of disease, which can be verified by the relevant laboratory values. According to the ABC5 consensus, evidence of visceral metastases is not sufficient to be described as a visceral crisis. To meet the criteria, vital organs must be compromised to such an extent that reliable therapy is required otherwise the patient will die. The ABC5 consensus used the definitions of visceral crisis of the liver and of the lung as examples:

- A visceral crisis of the liver is defined when bilirubin levels increase very rapidly (> $1.5 \times$ upper limit of normal [ULN]) without the presence of Gilbert syndrome (i.e.: Meulengracht syndrome) or biliary tract obstruction. 
- Table 2 Predictive factors for the treatment of metastatic breast cancer (source: [1], with the kind permission of the AGO Breast Committee).

\begin{tabular}{|c|c|c|c|c|}
\hline \multirow[t]{2}{*}{ Therapy } & \multirow[t]{2}{*}{ Factor } & \multicolumn{2}{|c|}{ Oxford } & \multirow[t]{2}{*}{ AGO } \\
\hline & & LoE & GR & \\
\hline \multirow[t]{3}{*}{ - Endocrine therapy } & ER/PR (primary tumor, better: metastasis) & $1 \mathrm{a}$ & A & ++ \\
\hline & Response to prior therapy & $2 b$ & B & ++ \\
\hline & Autocrine receptor mutation (ESR1) & $2 b$ & B & + \\
\hline - Chemotherapy & Response to prior therapy & $1 b$ & A & ++ \\
\hline - Anti-HER2 therapy & HER2 (primary tumor, better: metastasis) & $1 \mathrm{a}$ & A & ++ \\
\hline $\begin{array}{l}\text { - Immune checkpoint inhibitors } \\
\text { (atezolizumab) }\end{array}$ & $\begin{array}{l}\text { PD-L1 IC positivity" in TNBC } \\
\text { (primary tumor or metastasis) }\end{array}$ & $1 \mathrm{~b}$ & B & + \\
\hline - PARP inhibitors & gBRCA1/2 mutations & $1 \mathrm{a}$ & A & ++ \\
\hline - Bone-modifying drugs & Bone metastasis & $1 \mathrm{a}$ & A & ++ \\
\hline - Any therapy & CTC monitoring & $1 \mathrm{~b}$ & A & $+^{*}$ \\
\hline \multicolumn{5}{|l|}{${ }^{*}$ in clinical studies } \\
\hline \multicolumn{5}{|c|}{$\# \geq 1 \%$ determined on immune cells (IC) with SP142 (see chapter on Pathology [1]) } \\
\hline \multicolumn{5}{|c|}{ CTC: circulating tumor cells, PDL-1: programmed cell death ligand-1, TNBC: triple-negative breast cancer } \\
\hline
\end{tabular}

- A visceral crisis of the lung is present if dyspnea at rest increases more rapidly than can be relieved by pleural drainage (level of evidence [LoE]: expert opinion/NA).

The German group of experts agrees with this clarification of the $A B C 5$ definition of a visceral crisis.

\section{The challenge of long-term survival}

Thanks to new treatment options, increasing number of patients with advanced or even metastatic disease still have a chance of surviving for several years. Precision medicine may even offer the prospect of long-term survival. This raises questions about the appropriate long-term care of such patients.

For patients with advanced breast cancer and disease that is stable over the long term or who are even in complete remission, the majority (83.3\%) of $A B C 5$ panelists recommend regular adequate imaging of the breast during follow-up examinations. They point out that early breast lesions cannot always be imaged adequately using staging computed tomography or PET/CT scans (LoE/grading of recommendations [GoR]: expert opinion/C).

From a German perspective, breast examinations, with subsequent imaging where necessary, are part of the standard staging of patient with stable disease [1]. The rationale for this is local control of disease. Potential secondary tumors, which may have a different tumor biology, need to be detected as early as possible to adjust the therapy where necessary.

\section{Statements on Systemic Therapy}

\section{Relevant factors for the treatment decision}

Tumor biology plays an increasingly important role in treatment decisions. The determination of hormone receptor (HR) and HER2 status is an established procedure. In addition, the $A B C 5$ panelists $(95.1 \%)$ recommend testing tumor tissue for PIK3CA mutations and germline genotyping of BRCA 1 and BRCA2 genes
( $g B R C A)$. In triple-negative breast cancer (TNBC), the tumor or metastasis should be tested for the expression of PD-L1 (programmed cell death ligand-1) (see chapter on "Precision Medicine" and $>$ Table 2). According to the ABC5 consensus, the respective tests should only be carried out if the appropriate targeted substances are available to ensure that testing will have therapeutic consequences.

Additional factors also need to be taken into account when making treatment decisions: previous therapies and their toxicity, disease-free interval, tumor burden (number and site of metastases), the patient's biological age and general condition including potential comorbidities (including organ dysfunctions), menopausal status (in the context of endocrine therapy), the pressure to treat (the need for a rapid response with control of symptoms), socioeconomic and psychological factors, patient preferences and the availability of therapies (LoE/GoR: expert opinion/A).

From a German perspective, the list compiled by the ABC5 panelists detailing mutations which patients should be tested for because of their relevance for treatment should be expanded by the addition of testing for ESR 1 mutations (a possible indication of resistance to aromatase inhibitors) and the detection of NTRK (neurotrophic tyrosine receptor kinase) gene fusion (use of selective TRK [tropomyosin receptor kinase] inhibitors). Larotrectinib, the first TRK inhibitor, has been available since October 2019 to treat solid tumors with NTRK gene fusion. The German experts assume that tumor-agnostic indications (i.e., indications that are not specific to a particular tumor entity) will play an increasingly important role in the near future. NTRK gene fusion is mainly found in a histological subtype of secretory breast carcinoma.

\section{Metronomic chemotherapy}

The German experts agree with the majority vote (97.6\%) of the ABC5 panelists that metronomic chemotherapy can be an option if a rapid tumor response is not the primary goal. According to the $\mathrm{ABC} 5$ vote, possible regimens could consist of a combination of low-dose cyclophosphamide and methotrexate and the metro- 
nomic use of capecitabine or vinorelbine. The German view is that only evidence-based metronomic regimens should be used which are as effective as standard regimens. The German experts recommend the following metronomic therapies [8-16]:

- capecitabine: $500 \mathrm{mg}, 2-3$ times daily,

- vinorelbine $30 \mathrm{mg}$ daily or every 2 nd day,

- cyclophosphamide $50 \mathrm{mg}$ daily plus methotrexate $2.5 \mathrm{mg}$ every two days, or alternatively cyclophosphamide $50 \mathrm{mg}$ daily plus methotrexate $2.5 \mathrm{mg}$ BID on days $1+4$ per week [17]

- VEX regimen: cyclophosphamide $50 \mathrm{mg}$ (p. o.) daily, capecitabine $500 \mathrm{mg}$ (р. о.) 3× daily, vinorelbine $40 \mathrm{mg}$ (p. o.) 3× week.

\section{Use of bevacizumab}

The use of bevacizumab in addition to chemotherapy was controversially discussed by the $A B C 5$ panelists. According to the proposed $A B C 5$ statement, the use of bevacizumab should be limited to selected cases and is not recommended beyond first-line and second-line therapy. The statement also noted that in controlled clinical trials of metastatic breast cancer, the additional administration of bevacizumab only led to significantly increased progression-free survival but, to date, did not result in any increase in overall survival, while at the same time the potential toxicity was quite significant [18-20]. A narrow majority (52.6\%) of $A B C 5$ panelists rejected this negative statement on bevacizumab $(5.2 \%$ abstentions). In contrast to Germany, in the USA the FDA (Food and Drug Administration) has revoked the approval of the firstline use of bevacizumab to treat metastatic HER2-negative breast cancer patients.

This means that the old statement (ABC4 consensus) [3] remains valid but the emphasis is on the first-line use of bevacizumab. Accordingly, bevacizumab is an option for metastatic HER2negative breast cancer in addition to first-line chemotherapy. In the absence of predictive factors, the decision whether or not to administer bevacizumab must be taken on an individual basis. This is consistent with the recommendations of the AGO Breast Commission [1]. The German experts support a first-line indication for the use of bevacizumab, and this corresponds to the approval issued in Europe. The German experts add that the chemotherapy partner will also affect the use of bevacizumab. In Germany, bevacizumab has been approved for the first-line treatment of metastatic HER2-negative breast cancer in combination with paclitaxel or capecitabine.

\section{Hormone Receptor-positive, HER2-negative (HR+/HER2-) Breast Cancer}

Data on the use of CDK4/6 inhibition has substantially increased in the last two years. There are now prospective studies showing a survival benefit following therapy consisting of the combination of a CDK4/6 inhibitor and an endocrine therapy compared to endocrine therapy alone [21,22]. In light of this new data, the ABC5 panelists defined endocrine-based combination therapy with an CDK4/6 inhibitor as the standard of care for HR+/HER2- advanced breast cancer patients ( $97.4 \%$ agreement). In addition to the survival benefit, the positive vote also referenced the good tolerability overall of the CDK4/6-based combination therapy and the as- sociated good and often even improved health-related quality of life of patients.

According to the $A B C 5$ panelists, combination partners of CDK4/6 inhibitors include aromatase inhibitors (AI) or fulvestrant. Both combination regimens can be widely used as first-line or second-line therapy to treat de-novo metastatic and recurrent advanced breast cancer, irrespective of whether primary or secondary acquired endocrine resistance is present (see $A B C$ definition [3]) and irrespective of menopausal status. Premenopausal patients additionally require a $\mathrm{GnRH}$ (gonadotropin-releasing hormone) analogue. CDK4/6 inhibition is also an effective therapy for men with advanced breast cancer and should be combined with a GnRH analogue. The German experts agree with these statements. They add that for peri- and premenopausal patients, tamoxifen (plus a GnRH agonist) can also be a combination partner of a CDK4/6 inhibitor.

\section{Importance of ESMO-MCBS scores}

As part of the $A B C 5$ consensus, all $A B C 5$ panelists agreed to the use of the ESMO-MCBS (ESMO Magnitude of Clinical Benefit Grading Scale) [23] to evaluate currently available CDK4/6 inhibitor therapies and show the differences between individual options. The panelists justify the different evaluations by pointing to the respective trial and follow-up data. Accordingly, the first-line use of ribociclib plus endocrine therapy in premenopausal patients achieved the highest score (MCBS 5) because of the efficacy benefits with regard to median progression-free survival (PFS) and overall survival and concurrent improvement in health-related quality of life.

\section{ESMO-MCBS 5}

- First-line therapy with ribociclib plus endocrine therapy for premenopausal patients (efficacy score 4 [PFS/OS], improved quality of life)

\section{ESMO-MCBS 4}

- Second-line therapy with palbociclib/fulvestrant (efficacy score 3 [PFS/OS], improved quality of life),

- First-line and second-line treatment with ribociclib/fulvestrant (efficacy score 4 [PFS/OS]; no improvement in quality of life),

- Second-line therapy with abemaciclib (efficacy score 3 [PFS/ OS], no improvement in quality of life).

\section{ESMO-MCBS 3}

- First-line treatment with palbociclib/AI (efficacy score 3 [PFS], no improvement in quality of life) or abemaciclib/Al (efficacy score 3 [PFS], no data on quality of life), with each combined with an Al.

- First-line treatment with ribociclib/Al in postmenopausal patients (efficacy score 3 [PFS], no improvement in quality of life).

In Germany, the ESMO-MCBS is still not widely used. The ESMOMCBS is a scoring system used for clinical and economic evaluation, particularly of new drugs, and can also be used, if necessary, to provide a general assessment of a drug's clinical importance $[24,25]$. The German experts emphasize that the ESMO-MCBS does not play any role in individual treatment decisions. 
According to the German experts, in a homogeneous healthcare system the score should not be used to make treatment decisions for or against a specific CDK4/6 inhibitor. The AGO recommendation [1] assesses all 3 currently available CDK4/6 inhibitors as equivalent as it assumes a class effect for the three substances. The German experts emphasize that CDK4/6-based endocrine combination therapy should be discussed with patients with $\mathrm{HR}+$ /HER2- advanced breast cancer.

\section{CDK4/6 inhibition: for which line of therapy?}

The $A B C 5$ panel voted unanimously $(100 \%)$ in favor of using CDK4/6 inhibitors preferentially as a first-line therapy and defined it as the first-line standard of care for HR+/HER2- advanced breast cancer. Nevertheless, endocrine therapy alone may be indicated as the first-line therapy in selected cases. In such cases, this will have to be discussed with the patient, who must be fully informed about the therapy. The German experts refer to the current AGO recommendation which defines endocrine-based combination therapy as the first-line standard of care [1]. In Germany, CDK4/6 inhibitors are increasingly being used as a first-line therapy in clinical practice [26].

The SONIA trial (NCT03425838), an ongoing, multicenter, randomized phase III trial, uses an endocrine-based combination therapy with an CDK4/6 inhibitor either as a first-line or secondline approach to treat HER2-/HR+ advanced breast cancer, with the CDK4/6 inhibitor administered either after endocrine therapy alone or followed by endocrine therapy alone. The trial compares the two sequences [27].

\section{No maintenance therapy with CDK4/6 inhibition}

There is currently no data on the use of endocrine-based combination therapy with a CDK4/6 inhibitor as maintenance therapy after concluding chemotherapy (LoE/GoR: NA/D). If an endocrine maintenance therapy is considered, then endocrine monotherapy is indicated. After an intensive discussion, $65.7 \%$ of the $A B C 5$ panelists agreed with this statement.

From a German perspective, the first thing that needs to be clarified in a first-line setting is whether chemotherapy is indicated. If this is the case, then it is important to await the effect of chemotherapy and not to prematurely use a highly effective treatment option such as an endocrine-based combination therapy with an CDK4/6 inhibitor. Endocrine-based combination therapy with an CDK4/6 inhibitor should only be used if disease progresses after primary chemotherapy.

\section{Endocrine therapy sequence: numerous options}

No optimal endocrine therapy sequence has yet been defined. It depends, among other things, on previous therapy, tumor burden, and patient preference. According to the ABC5 panel, possible therapy options include endocrine-based combination therapies (Al or fulvestrant) with a CDK4/6 inhibitor or with fulvestrant or tamoxifen plus everolimus, endocrine monotherapy (AI, fulvestrant, tamoxifen) or a combination of fulvestrant and alpelisib (in patients with PIK3CA mutation). For later lines of therapy, the $A B C 5$ panelists see megestrol acetate and estradiol and, where applicable, the repeat use of endocrine therapy as options.
The German experts add that the therapy sequence also depends on the quality of response to previous therapies. In Germany, the use of progestins or low-dose estrogens is considered obsolete because of the many other therapy options and alternatives. The German experts point out that currently there is evidence-based data to support the continuation of endocrine-based therapy (treatment beyond progression [TbP]; continuation of treatment with CDK4/6 inhibitor or mTOR inhibitor, change of endocrine combination partner). Alpelisib in combination with fulvestrant will only become an option for patients with PIK3CA-mutated tumors after it has been approved for clinical use.

In a separate statement focusing on later lines of therapy, the majority of $A B C 5$ panelists (97.5\%) voted that monotherapy with abemaciclib can also be a therapy option instead of endocrine monotherapy after the second line of therapy. In this context, the $A B C 5$ panelists noted that the reinduction of therapy is often considered as an option and implemented in clinical practice, even though there are no robust data which support this approach. The latter is in line with the above comments by the German experts and the recommendations of the AGO [1].

\section{Endocrine-based combination or chemotherapy?}

There are currently a number of ongoing clinical trials on metastatic HR+/HER2- breast cancer which compare an endocrinebased combination therapy with mono-chemotherapy. The initial results of randomized phase II trials indicate that endocrine-based combinations are at least comparable or even superior to monochemotherapy in terms of efficacy and safety (LoE/GoR: II/B) [29, 30]. The $A B C 5$ panelists and the German experts agree that an endocrine-based combination therapy is the preferred therapy option to treat HR+/HER2- metastatic breast cancer.

\section{Nonsteroidal AI plus fulvestrant}

In a US-based phase III trial conducted by the Southwest Oncology Group (SWOG S0226; NCT00075764), the endocrine combination therapy of a nonsteroidal Al (anastrozole) with fulvestrant was found to significantly improve both median PFS and median overall survival (OS) in postmenopausal patients with HR+/HER2metastatic breast cancer in a direct comparison with an $\mathrm{Al}$ monotherapy (anastrozole) [31]. However, later studies with a comparable design were unable to confirm this benefit [32,33].

According to a subgroup evaluation of the SWOG trial [31], the PFS/OS benefit is limited to patients who have not received prior adjuvant hormone therapy (tamoxifen), which is why an endocrine combination therapy may only represent an option for this specific subgroup of patients. The ABC5 panelists intensively discussed this statement at the conference. Even for this subgroup of patients with no previous adjuvant hormone therapy, just under two thirds $(60.0 \%)$ of the $A B C 5$ panelists consider endocrine combination therapy only to be an option if endocrine-based combination therapy with a CDK4/6 inhibitor is not available.

From a German perspective, the data of the SWOG trial are not relevant for clinical practice in Germany. The German experts mention the consistent data and study results for CDK4/6 inhibitors [21,22]. Moreover, the SWOG trial has specific weaknesses [21]: 
1. The standard dose of fulvestrant is $500 \mathrm{mg}$; the dose of $250 \mathrm{mg}$ fulvestrant used in the trial is therefore too low;

2. The PFS/OS benefit was only significant in the subgroup of patients who had not previously received endocrine therapy.

\section{HER2-positive Breast Cancer: Use of Neratinib}

At the time of voting at the $\mathrm{ABC} 5$ conference, the combination of neratinib and capecitabine had not been approved to treat patients with HER2-positive (HER2+) metastatic breast cancer. The ABC5 panelists therefore almost unanimously (90\%) agreed not to recommend the combination of neratinib and capecitabine for routine use in clinical practice to treat such patients (LoE/GoR: I/ D). Since then, the FDA (Food and Drug Administration) has approved the combination to treat patients with metastatic HER2positive breast cancer who have undergone at least two prior anti-HER2 therapies. The FDA approval was based on the results of the NALA trial [34].

In the randomized phase III NALA trial [34], the combination of neratinib and capecitabine achieved a median PFS benefit of 2.2 months in patients with HER2+ metastatic breast cancer who had received multiple prior therapies compared to the combination of lapatinib and capecitabine, but it did not result in any significant survival benefit. The ABC5 panelists emphasized the need for further clinical trials on the use of neratinib/capecitabine to treat patients with advanced breast cancer including patients with brain metastases. In their statement they also pointed out that neratinib/capecitabine had not been compared with trastuzumab/capecitabine. Trastuzumab/capecitabine shows a survival benefit compared to lapatinib/capecitabine [35].

From a German perspective, a statement on the clinical use of neratinib/capecitabine for HER2+ metastatic breast cancer is not necessary, as the combination is not currently approved for use in Europe. Should the combination be approved, then neratinib/ capecitabine represents a possible alternative as a late line of therapy for HER2+ metastatic breast cancer.

\section{Alpelisib in PIK3CA-mutated breast cancer}

A PIK3CA mutation is found in $30-40 \%$ of all HR+/HER2- advanced breast cancers. This is followed by increased activation of the alpha-isoform of phosphoinositide-3 kinase (PI3K) which stimulates tumor growth. It also appears that PIK3CA-mutated breast cancer responds less well to endocrine therapy. PI3K inhibitors such as alpelisib offer a promising new perspective for the treatment of patients with PIK3CA-mutated breast cancer. In the randomized phase III SOLAR-1 trial, alpelisib in combination with fulvestrant almost doubled the median PFS of postmenopausal patients with $\mathrm{HR}+/ \mathrm{HER} 2-$ advanced breast cancer and PIK3CA mutation (HR $0.65 ; \mathrm{p}<0.001$ ) [28]. All patients had experienced disease progression after previous endocrine therapy. The primary endpoint of the study was progression-free survival (PFS).

At present, alpelisib has not (yet) been approved for use in Europe to treat PIK3CA-mutated breast cancer. Already prior to its approval, just under $90 \%$ (87.8\%) of $A B C 5$ panelists considered the combination of alpelisib and fulvestrant as a treatment option for postmenopausal patients with HR+/HER2- metastatic breast cancer if the patient had a PIK3CA mutation on exon 9 or 20 , had received prior treatment with an $\mathrm{Al}$, and had adequate $\mathrm{HbA} 1 \mathrm{C}$ levels. However, the $A B C 5$ panelists remark that because of side effects associated with alpelisib (risk of treatment-induced diabetes mellitus), the benefits and risks of this treatment decision must be weighed up very carefully. To date, no survival benefit has been reported for this combination. As only around $7 \%$ of patients in the SOLAR-1 trial had been previously treated with a CDK4/6 inhibitor, it is also unclear how effective the combination is in patients who have received prior treatment with a CDK4/6 inhibitor.

From a German perspective, as long as the combination has not been approved, alpelisib is not recommended in clinical practice to treat HR+/HER2- metastatic breast cancer. The German experts also point out that treatment with alpelisib/fulvestrant is also associated with an increased risk of hyperglycemia. Although no patients with diabetes mellitus were included in the SOLAR-1 trial, grade 3 hyperglycemia occurred in just under one third of patients. These patients were controlled with oral antidiabetic medication, but this side effect also led to a discontinuation of treatment in some cases [28].

Although approval of the combination is still pending, the German experts recommend screening for diabetes prior to beginning treatment and during therapy. Patients at risk should be monitored by an multidisciplinary team. In addition, the German experts agree with the ABC5 panelists that if alpelisib is used, patients should additionally be given a non-sedative antihistamine. In the first two weeks after the start of therapy, there is an increased risk of skin complications (rash). The antihistamine can usually be discontinued after four weeks.

\section{TNBC: The Role of Immunotherapy}

Atezolizumab/nab-paclitaxel is the first immunotherapy/chemotherapy combination which is available for the first-line treatment of patients with metastatic triple-negative breast cancer (TNBC: ER-, PR-, HER2-) and PD-L1 expression on immune cells (PD-L1/ $I C \geq 1 \%$ ) [1]. The overwhelming majority (94.8\%) of ABC5 panelists consider the combination of atezolizumab and nab-paclitaxel to be an option for the first-line therapy of PD-L1/IC+ advanced TNBC (MCBS 3; LoE/GoR. I/B). The combination led to a significant prolongation of PFS (primary study endpoint) in the phase III IMpassion-130 approval trial [36] compared to chemotherapy alone (nab-paclitaxel) in patients with PD-L1+ advanced TNBC (HR 0.62; $p<0.0001)$. The final survival data are not yet available [36].

The use of immunotherapy as a monotherapy for advanced TNBC is not considered an option by the majority (89.4\%) of $A B C 5$ panelists in later lines of therapy because response rates are low (LoE/GoR: I/E). In principle, the German experts agree and state that first-line use of atezolizumab/nab-paclitaxel is preferable. Based on data from the KEYNOTE-119 trial [37], the German experts recommend in individual cases where patients have already received multiple prior treatments, a monotherapy, for example with pembrolizumab, instead of mono-chemotherapy. The prerequisite for this option is a combined positive score (CPS) of $\geq 20 \%$ in the tumor or in the metastases. It should be noted that monotherapy with pembrolizumab is currently not approved to treat metastatic TNBC in Germany. 
The overwhelming majority $(97.5 \%)$ of $A B C 5$ panelists and the German experts agree that, at present, outside clinical trials, immunotherapy is not an option for patients with subtypes of advanced breast cancer other than TNBC.

\section{TNBC: recommendation for PD-L1 testing}

The $A B C$ panelists and the German experts also agree that following the approval of atezolizumab/nab-paclitaxel as a first-line therapy for patients with PD-L1-+ advanced TNBC, PD-L1 testing must be carried out in patients with advanced TNBC. The ABC5 panelists only recommend testing if atezolizumab/nab-paclitaxel is actually available and can be administered (LoE/GoR: I/A). The majority (97.4\%) recommend that testing is done using the Ventana companion diagnostic test with the SP142 antibody which was used in the approval study [36]. The cut-off value for a positive PD-L1 status is a PD-L1 expression of $\geq 1 \%$ on immune cells (LoE/GoR: I/A).

The German experts wish to add that different testing methods are needed for different checkpoint inhibitors. It is therefore important to consult with pathology department and with the relevant professional society concerning the relevant testing method. Information about testing methods which have been validated in studies or during the approval process is given in the respective product information and must be studied carefully. Other testing methods must be validated and compared with the original method.

\section{Approach for weakly positive HR status}

The tumor biology of cases with HR+/HER2- advanced breast cancer and a weakly positive HR status (only 1-10\% ER-positive cells) is assumed to be similar to that of advanced TNBC (LoE/GoR: III/B). For these patients (with 1-10\% ER-positive cells), the majority (94.8\%) of ABC5 panelists recommend not to focus exclusively on endocrine therapy options.

The German experts agree and refer to the treatment recommendations of the AGO [1] and the Brainmet Register Study of the BMBC (Brain Metastases in Breast Cancer Network Germany). The BMBC was created by the GBG (German Breast Group; Prof. Volkmar Müller, Hamburg) [38]. Patients with weakly HR-positive breast cancer are considered a special subgroup and defined as having "questionable endocrine sensitivity".

According to the AGO recommendations, patients can also receive endocrine-based treatment, where appropriate. However, their response to therapy must be closely monitored. The majority of these cancers biologically resemble basal-like breast cancer phenotypes. The German experts therefore advocate including patients with weakly HR-positive (ER < $10 \%$ ) advanced breast cancer in clinical studies on TNBC to validate the response to treatment.

\section{Focus on BRCA Germline Testing}

The German experts agree with the $A B C 5$ panelists that $g B R C A$ testing should be carried out at an early stage of advanced breast cancer, as the results have consequences for subsequent therapy. Primary panel testing is indicated for patients with a family history (of breast and/or ovarian cancer) and patients with TNBC aged less than 60 years irrespective of their family history (in Germany, the costs of such tests are only reimbursed for patients below the age of 50 years). It is worth discussing whether all women with HER2-negative disease and metastasis should be offered testing even if they have no family history of breast or ovarian cancer.

The German experts point out that detection of a gBRCA mutation is an indication for treatment with a PARP (poly [ADP-ribose] polymerase) inhibitor. They also note that in the event of a positive $g B R C A$ test, the patient's family should also be informed (subject to patient consent) and offered genetic counseling. In cases of metastatic disease, patient age does not affect the indication for $g B R C A$ testing. Although the incidence of $g B R C A$ mutations is low in older women, it remains therapeutically relevant. The German experts emphasize that from a therapeutic perspective, testing should only be done for BRCA1/2 mutation.

\section{Use of PARP inhibitors}

The two PARP inhibitors olaparib und talazoparib are therapy options for patients with HER2-negative advanced breast cancer and gBRCA mutation. Patients should have had prior (neo)adjuvant therapy. Patients with metastatic disease should have received prior anthracycline and/or taxane therapy and, if applicable, endocrine therapy. If chemotherapy is indicated for these patients, the ABC5 panelists (78.0\%) recommend initial monotherapy with a PARP inhibitor. Chemotherapy should only be administered if the PARP inhibitor has failed. The ABC5 panelists refer to the currently available data [39-41] whereby PARP inhibitors were found to achieve a longer median PFS compared to chemotherapy while also having a more favorable safety profile and therefore offering a better health-related quality of life (MCBS 4; LoE/GoR: I/A).

The German experts recommend a PARP inhibitor as early as possible when treating patients with advanced HER2-negative breast cancer. To date, an overall survival benefit was only reported in the OlympiAD study in a first-line setting $[39,40]$. As the data was only obtained from the analysis of the small subgroup of $g B R C A$-mutated patients, more survival data must be generated. The German experts regret that gBRCA mutation analysis in HER2- advanced breast cancer is currently not being carried out across Germany [42].

\section{Therapy sequence after detection of gBRCA mutation}

The data on the optimal therapy sequence for patients with HER2negative and $g B R C A$-mutated advanced breast cancer is currently still insufficient. This also applies to HR-positive gBRCA-associated advanced breast cancer. However, given the now documented survival benefit of an endocrine-based combination therapy with a CDK4/6 inhibitor [21,22], the majority $(90.2 \%)$ of the $A B C 5$ panelists recommend that initial treatment should consist of an endocrine-based combination with a CDK4/6 inhibitor, with a PARP inhibitor used as the second line of therapy. The German experts agree. The question regarding the optimal therapy sequence requires further evaluation.

In the randomized phase III BROCADE-3 trial [43], a PARP inhibitor (veliparib) was used for the first time as maintenance therapy to treat $g B R C A$-mutated metastatic breast cancer after successful platinum-based chemotherapy. One quarter of the patients who received veliparib maintenance therapy continued to be progres- 
- Table 3 Genomic factors relevant for the therapy decision in metastatic breast cancer (Source: [1], with the kind permission of the AGO Breast Commission).

\begin{tabular}{|c|c|c|c|c|c|c|}
\hline \multicolumn{7}{|c|}{ Diagnosis of mutations in $\mathrm{mBC}$ : precision medicine for targeted therapies } \\
\hline \multirow[t]{2}{*}{ Altered genes } & \multirow{2}{*}{ Therapeutic relevance } & \multirow[t]{2}{*}{ Gene region } & \multirow[t]{2}{*}{ Material } & \multicolumn{2}{|c|}{ Oxford } & \multirow[t]{2}{*}{ AGO } \\
\hline & & & & LOE & GR & \\
\hline BRCA1, BRCA2 & PARP inhibitor & All exons & $\begin{array}{l}\text { Germline: blood cells } \\
\text { Somatic: tissue }\end{array}$ & $\begin{array}{l}1 \mathrm{~b} \\
2 \mathrm{~b}\end{array}$ & $\begin{array}{l}A \\
B\end{array}$ & $\begin{array}{l}++ \\
+1-\end{array}$ \\
\hline PIK3CA & Alpelisib & Exons 7, 9 and 20 & $\begin{array}{l}\text { Primary tumor, metasta- } \\
\text { ses, plasma }\end{array}$ & $1 \mathrm{~b}$ & A & + \\
\hline $\begin{array}{l}\text { HER2 mutation } \\
\text { (irrespective of } \\
\text { HER2 status) }\end{array}$ & Neratinib, lapatinib & $\begin{array}{l}\text { Kinase and extracellular do- } \\
\text { mains; S310, L755, V777, } \\
\text { Y772_A775dup }\end{array}$ & $\begin{array}{l}\text { Primary tumor, metasta- } \\
\text { ses, plasma }\end{array}$ & 4 & $\mathrm{C}$ & $+1-$ \\
\hline ESR1 & Resistance to $\mathrm{Al}$ & Exons 4,7 and 8 & Metastases, plasma & $2 b$ & B & $+1-$ \\
\hline NTRK gene fusion & $\begin{array}{l}\text { Larotrectinib, entrecti- } \\
\text { nib }\end{array}$ & Fusion and splicing variants & $\begin{array}{l}\text { Tumor tissue, especially } \\
\text { secretory breast cancer }\end{array}$ & $2 a$ & B & + \\
\hline MSI & Pembrolizumab & Microsatellite instability & Tissue & $2 a$ & B & + \\
\hline
\end{tabular}

sion-free after 3 years. As veliparib is currently not approved for use, the experts declined to vote on the importance or a recommendation of this approach.

\section{Prospects for Precision Medicine}

Precision medicine is a new therapeutic approach in oncology. The approach focuses on genomic and molecular changes which serve as prognostic and/or predictive markers, underlie tumor development, and promote proliferation metastasis. Genomic/molecular changes/mutations often also serve as targets for new substances ( $\vee$ Tables 2 and 3 ) [1].

\section{Value of ctDNA analysis}

- The ABC5 panelists (97.2\%) and German experts agree that detection of cell-free tumor DNA (ctDNA) in the blood of tumor patients is currently not yet ready for routine clinical use as a reliable, early means of detecting tumor progression.

- However, the majority (92.6\%) of ABC5 panelists consider ctDNA analysis to be an option for detecting PIK3CA mutations and making decisions about the appropriate therapy (e.g. the use of alpelisib) (LoE/GoR: II/A). As alpelisib is currently not yet approved for use in Germany, the German perspective is that ctDNA analysis is not needed at present. The German experts recommend mutation analysis of tumor tissue, where applicable. This can be requested from the pathologist in individual cases. If a PIK3CA mutation is detected, participation in a managed access program (MAP) for alpelisib should be considered.

- The German experts agree with the ABC5 statement that testing for PIK3CA mutation (exon $9+20$ ) should be carried out in tumor tissue (primary tumor or metastasis) or by means of ctDNA analysis as soon as alpelisib has been approved. However, ctDNA mutation analysis is neither established nor validated in Germany. If no tumor tissue was archived and liquid biopsy testing did not lead to an unambiguous result, a tumor biopsy specimen should be tested for PIK3CA mutation (LoE/GoR: I/B).

\section{No recommendation for ESR1 mutation testing?}

According to the ABC5 consensus, ESR 1 mutation status currently plays no role in routine clinical practice and the treatment of $\mathrm{HR}+$ advanced breast cancer. ESR1 determination is therefore not recommended (90.2\%), neither as a means of detecting disease progression nor as a means of choosing the appropriate endocrine therapy (switching from Al to fulvestrant or SERDs [selective estrogen receptor degraders]) (LoE/GoR: I/D). The German experts would like to add that the value of ESR 1 mutation status for therapy with a CDK4/6 inhibitor is unclear, which is why the importance of determining ESR1 mutation status has not been defined for Germany. Retrospective data indicate a reduced efficacy of Al monotherapy. This requires further validation.

\section{Specific Metastatic Sites}

\section{Bone metastasis}

With regard to bone metastasis and the use of bone-modifying agents, the $A B C 5$ panelists refer to the Clinical Practice Guidelines of the ESMO on supportive therapy [44], the contents of which are generally consistent with the recommendations of the AGO Breast Commission [1]. According to these recommendations, patients with advanced breast cancer and bone metastasis should routinely be treated with a bisphosphonate or denosumab in addition to receiving oncologic systemic therapy and/or radiotherapy (LoE/GoR: I/A). Patients who receive zoledronic acid every 4 weeks over a period of 6 to 12 months and whose disease is stable can be switched to 3-monthly administration of zoledronic acid (LoE/ GoR: I/B). Because of the lack of data, this does not apply to denosumab (LoE/GoR: NA/D).

If there are no contraindications, patients should also receive supplementation with calcium and, above all, Vitamin $D_{3}$ (LoE/ GoR: I/A). Supplementation with calcium and Vitamin- $D_{3}$ is mandatory for patients being treated with denosumab. If supplementation is not possible, for example, because of contraindications, then denosumab must not be used. 
The optimal duration of bone-modifying therapy is still not clear. The risk of osteonecrosis of the jaw and skeletal events such as bone fractures increases in cases with longstanding stable disease and long duration of therapy. Longer therapy intervals (e.g., 6-monthly administration of bisphosphonate) should be considered in this situation and discussed with the patient $[45,46]$.

\section{Leptomeningeal disease}

Leptomeningeal disease (LMD) is a rare but serious form of metastasis which can be accompanied by extensive neurological complications. There is currently no standard procedure for this situation. According to the $\mathrm{ABC} 5$ consensus, in addition to best supportive care, therapy options include radiotherapy or chemotherapy. The therapy decision should be made by an interdisciplinary team (tumor board) and must take the patient's prognosis into account (LoE/GoR: expert opinion). The ABC5 panelists recommend focal radiation for clearly delineated, specifically symptomatic lesions. Whole brain radiotherapy (WBRT) can be considered for extensive nodular or symptomatic LMD (in each case LoE/GoR: expert opinion). The German experts agree.

The ABC5 panelists point out that patients cannot expect any survival benefit or improvement of their quality of life from the intrathecal administration (i.e. direct administration into the cerebrospinal fluid [CSF]) of chemotherapy (if chemotherapy is indicated). In their statement they note that intrathecal chemotherapy does not delay CSF progression in any clinically relevant manner (LoE/GoR: ॥/D).

The German experts add that the indication for intrathecal chemotherapy must be defined very consistent. They agree with the $A B C 5$ panelists that intrathecal chemotherapy should only be considered (if at all) for patients with systemic stable disease and normal cerebrospinal fluid flow. The potential risk of substantial side effects needs to be weighed up very carefully (LoE/GoR: expert opinion). The German experts refer to the statements in the S3-guideline on the treatment of breast cancer [47].

\section{Supportive and Palliative Measures}

\section{Use of cannabis and opioids}

The use of cannabis for pain management has been discussed in oncology for many years. The ABC5 panelists (97.1\%) state that the value of using cannabis to manage pain and symptoms requires further study. The panel emphasizes that cannabis must not be used to replace evidence-based pain therapy such as morphine (LoE/GoR: I/C).

The German experts agree and wish to add that pain therapy must be carried out in accordance with the standards of the German S3-guideline on palliative medicine [48]. The guidelines accept the use of cannabinoids as a co-analgesic but not as a replacement for morphine preparations.

The ABC5 panelists and the German experts are aware that not all tumor patients have unlimited access to morphine preparations in every country worldwide. It is necessary to create conditions for adequate management of all tumor patients worldwide.

\section{Managing gynecological complaints}

The German experts fully agree with the ABC5 consensus statements on managing gynecological complaints. Hormone replacement therapy is not indicated to treat postmenopausal symptoms in patients with advanced breast cancer. This particularly apples to patients with $\mathrm{HR}+$ advanced breast cancer.

The ABC5 panelists consider the following measures to be valid alternatives:

- General postmenopausal complaints: mind-body interventions, exercise, and cognitive behavioral therapy are effective non-pharmacological options (LoE/GoR: I/B).

- Hot flushes: pharmacological options include venlafaxine, oxybutynin, gabapentin and clonidine (LoE/GoR: I/B).

- Sleep disturbances: the administration of melatonin can help (LoE/GoR: II/C)

There is no convincing evidence that herbal medicines improve postmenopausal complaints. Moreover, it is important to consider potential interactions with medications (LoE/GoR: I/D).

\section{Sexual health/sexual life}

For the first time, the $A B C 5$ consensus has also addressed the issue of sexuality and the sexual health of patients with breast cancer. The ABC5 panelists emphasize the importance of this topic and the need to overcome feelings of insecurity and shame. This requires a far wider definition of sexuality than sexual intercourse alone. The potentially limited life expectancy of patients with advanced breast cancer makes physical contact, affection, emotional support and empathetic talks particularly important.

The sexual health of many patients deteriorates over the course of disease. These women require special attention and care. In many cases, the situation can be improved by honest discussions and suggestions, which also have a positive effect on the patient's quality of life. The $A B C 5$ panelists recommend the use of standardized measurement instruments (validated questionnaires) which can help to estimate the extent of the negative impact on patients (LoE/GoR: expert opinion/NA).

\section{Dealing with dyspareunia}

Dyspareunia is often caused by a dry vagina. The $A B C 5$ panelists recommend using hormone-free lubricants as a primary measure (LoE/GoR: II/B). Another alternative is the vaginal application of low-dose estrogen preparations (LoE/GoR: II/B). It is unclear whether the topical application of testosterone can provide relief. The German experts agree with all of these points.

\section{ABC5 Statement of Patient Advocates}

As in previous $A B C$ conferences, patient advocates from Europe, Asia, the Middle East, Africa, Australia, and North, South and Central America also attended the ABC5 conference and formulated their concerns. The panelist and patient advocate Shirley A. Mertz from the USA presented the most important demands of patient advocates during the plenary session of the ABC5 conference.

To provide individualized treatment and support, it is important that the physician sees the patient as a person and does not just treat the disease. A consultation time of 10-15 minutes is not 
sufficient. "Give your patients the opportunity to talk and get to know them with their fears, desires and hopes," Mertz urged. When making therapy decisions it is important to know what kind of person is sitting in front of you.

Mertz pointed out that it is important to use comprehensible language to ensure that patients understand all they are told. Most patients want to know why a specific decision for treatment was taken and they usually want to be involved in the decision. "Make us your partner in the fight against cancer," Mertz appealed.

The conversation between physician and patient should always start with a personal lead-in, urged Mertz. "Ask us how we are feeling, how we are coping with therapy, whether we are in pain or have other complaints, and take them seriously." Medical results and further procedures should only be discussed afterwards.

Mertz reminded listeners that advanced cancer disease represents a particular psychological challenge for patients who know that a cure is no longer possible. "Put yourself in our position and try to understand our needs and vulnerabilities."

"We know that our disease also represents a challenge for the physician," Mertz summarized. Mutual understanding and honest conversations are an important foundation for both sides of a good doctor-patient relationship. On behalf of the patient advocates Mertz expressed her thanks for the opportunity to take part in the $A B C 5$ conference and have an international exchange between patient advocates and with physicians.

Following the $A B C 5$ consensus conference, there was a meeting of the $A B C$ Global Alliance, which was launched by the ESO in 2016. The ABC Global Alliance has been initiated by patient advocates but many physicians and industry are also involved. The aim is to help provide access to improved therapies and make them available to patients worldwide. The German patient advocate and $A B C 5$ panelist Renate Haidinger was newly elected as director of the General Assembly of the ABC Global Alliance. During this session, the Global Alliance was separated out from the ESO and established as an independent global organization.

\section{Conclusion and Outlook}

The $A B C 5$ conference is a platform for important discussions about the latest developments in advanced and metastatic breast cancer. The $A B C$ consensus provides an important contribution towards standardizing the treatment of advanced breast cancer on an international level and optimizing treatment worldwide. The $A B C$ conference is therefore useful in addition to the St. Gallen Consensus Conference on early-stage breast cancer. The next ABC6 consensus conference will be held in Lisbon on November 4-6, 2021.

\section{Acknowledgements}

The meeting of the German specialists in Lisbon was supported and organized by AURIKAMED Institut GmbH. The authors would like to thank Birgit-Kristin Pohlmann, Nordkirchen, for her editorial contributions to the manuscript. The authors are solely responsible for the final release of the contents of this paper.

\section{Conflict of Interest}

Prof. Michael Untch: honoraria paid to his employer (for adboard participation, presentations) and travel grants from Amgen, AstraZeneca, BMS, Celgene, Daiichi Sankyo, Eisai, Janssen Cilag, Johnson \& Johnson, Lilly Deutschland, Lilly International, MSD Merck, Mundipharma, Myriad Genetics, Odonate, Pfizer, PUMA Biotechnology, Riemser, Roche, Sanofi Aventis, Sividon Diagnostics, Teva Pharmaceuticals Ind. Ltd.

PD Dr. med. Rachel Würstlein received honoraria from Agendia, Amgen, AstraZeneca, Boehringer Ingelheim, Carl Zeiss, Celgene, Daiichi Sankyo, Eisai, Genomic Health, GSK, Lilly, MSD, Mundipharma, NanoString, Novartis, Odonate, Paxman, Palleos, Pfizer, Pierre Fabre, Puma Biotechnology, Riemser, Roche, Sandoz/Hexal, Seattle Genetics, Tesaro Bio, Teva.

Prof. Diana Lüftner received honoraria from Amgen, AstraZeneca, Celgene, Daiichi Sankyo, Esai, Genomic Health, GSK, Lilly, MSD,

Mundipharma, Novartis, Pfizer, Pierre Fabre, Puma Biotechnology, Riemser, Roche, Tesaro Bio, Teva.

Renate Haidinger has no conflict of interest.

Prof. Peter A. Fasching received honoraria from Roche, Pfizer, Celgene, Daiichi Sankyo, Merck Sharp \& Dohme, Myelo Therapeutics, Eisai, Puma, Lilly, Novartis, AstraZeneca, and his institution received research funding from BionTech and Cepheid.

Prof. Christoph Thomssen received honoraria from Amgen, AstraZeneca, Celgene, Daiichi Sankyo, Eisai, Lilly, MSD, Mundipharma, MEDA,

Novartis, Roche, Tesaro, Vifor.

Prof. Nadia Harbeck received honoraria for lectures and/or consultancy work from Amgen, AstraZeneca, BMS, Celgene, Daiichi Sankyo, Lilly, MSD, Novartis, Odonate, Pierre Fabre, Pfizer, Roche, Sandoz/Hexal, Seattle Genetics.

Dr. med. Doris Augustin has no conflict of interest.

Dr. med. Susanne Briest has no conflict of interest.

Dr. med. Johannes Ettl received honoraria from AstraZeneca, Roche, Celgene, Novartis, Lilly, Pfizer, Pierre Fabre, Teva and travel grants from Celgene, Lily, Novartis, Pfizer, Teva, Pierre Fabre.

Prof. Frank Förster received honoraria from Roche, Novartis, Astra-

Zeneca, Eisai, Lilly, Pfizer, Tesaro, MSD, Celgene.

Dr. med. Christian Kurbacher received honoraria from Amgen, Axios, Eli Lilly, Hilotherm, Mundipharma, NewCo, Novartis, Pfizer, Riemser, Roche, Tesaro. Research funding from AstraZeneca, Axios, MSD Sharp \& Dohme, NewCo, Novartis, Pfizer, PharmaMar, Riemser, Seattle Genetics. Honoraria from Amgen, Eli Lilly, Novartis, Mundipharma, Pfizer, PharmaMar, Riemser, Roche, Tesaro; travel grants and other expenses from Amgen, Hexal, Pfizer, PharmaMar, Tesaro, Teva Oncology. Prof. Hans-Joachim Lück has no conflict of interest.

Dr. med. Norbert Marschner received speaker's fees from Lilly, Roche, Novartis, Clovis, GSK, Amgen, Mylan, Eisai, Mundipharma, Novella, SEAGEN, and travel grants from Lilly, Roche.

Dr. med. Lothar Müller received travel grants from octapharm and Medac.

Prof. Volkmar Müller received honoraria from Amgen, AstraZeneca, Celgene, Daiichi-Sankyo, Eisai, Pfizer, MSD, Novartis, Roche, Teva, and honoraria for consultancy work from Genomic Health, Hexal, Roche, Pierre Fabre, Amgen, ClinSol, Novartis, MSD, Daiichi-Sankyo, Eisai, Lilly, Tesaro, Nektar.

Dr. med. Isabel Radke received honoraria and/or travel grants from Amgen, AstraZeneca, Celgene, Genomic Health, Novartis, Pierre Fabre, Pfizer, Roche, Teva.

Prof. Eugen Ruckhäberle received honoraria from Amgen, AstraZeneca, Pharma Mar, Celgene, Daiichi Sankyo, Eisai, GSK, Lilly, MSD, Novartis, Pfizer, Pierre Fabre, Riemser, Roche, Sandoz/Hexal, Seattle Genetics, Tesaro Bio, Clovis Oncology, Teva.

Dr. med. Iris Scheffen received honoraria from Amgen, Celgene, MSD, Novartis, Pfizer, Roche.

Eva Schumacher-Wulf has no conflict of interest.

Dr. med. Moritz Schwoerer received honoraria for adboard participation from Roche. 
Dr. med. Dieter Steinfeld-Birg received honoraria from Amgen, Hexal, Roche, Teva, Novartis.

Dr. med. Katja Ziegler-Löhr received honoraria from Celgene, Novartis, Oncovis, Roche, Tesaro.

\section{References}

[1] AGO State-of-the-Art Empfehlungen Diagnose und Therapie des frühen und fortgeschrittenen Mammakarzinoms. Update 2020. Online: www. ago-online.de; last access: 04.03.2020

[2] Cardoso F, Senkus E, Costa A et al. ESO-ESMO 4th international consensus guidelines for advanced breast cancer (ABC 4). Ann Oncol 2018; 29: 1634-1657

[3] Harbeck N, Lüftner D, Marschner N et al. ABC4 Consensus: Assessment by a German Group of Experts. Breast Care (Basel) 2018; 13: 48-58

[4] Cardoso F, Costa A, Norton L et al. 1st International consensus guidelines for advanced breast cancer (ABC 1). Breast 2012; 21: 242-252. doi:10.1016/j.breast.2012.03.003

[5] Cardoso F, Costa A, Norton L et al. ESO-ESMO 2nd international consensus guidelines for advanced breast cancer (ABC2). Breast 2014; 23: 489502

[6] Cardoso F, Costa A, Senkus E et al. ESO-ESMO 3rd international consensus guidelines for advanced breast cancer (ABC 3). Breast 2017; 31: 244259

[7] Online: www.esmo.org/Guidelines/ESMO-Guidelines-Methodology; last access: 30.11.2019

[8] Stockler MR, Harvey VJ, Francis PA et al. Capecitabine Versus Classical Cyclophosphamide, Methotrexate and Fluorouracil As First-Line Chemotherapy for Advanced Breast Cancer. J Clin Oncol 2011; 29: 4498-4504

[9] Cazzaniga ME, Biganzoli L, Cortesi L et al.; Metronomic Chemotherapy in Advanced Breast Cancer Study Group. Treating advanced breast cancer with metronomic chemotherapy: what is known, what is new and what is the future? Onco Targets Ther 2019; 12: 2989-2997

[10] Cazzaniga ME, Pinotti G, Montagna E et al.; VICTOR Study Group. Metronomic chemotherapy for advanced breast cancer patients in the real world practice: Final results of the VICTOR-6 study. Breast 2019; 48: 716

[11] De Iuliis F, Salerno G, Taglieri L et al. On and off metronomic oral vinorelbine in elderly women with advanced breast cancer. Tumori 2015; 101: 30-35

[12] Fedele P, Marino A, Orlando L et al. Efficacy and safety of low-dose metronomic chemotherapy with capecitabine in heavily pretreated patients with metastatic breast cancer. Eur J Cancer 2012; 48: 24-29

[13] Krajnak S, Battista M, Brenner W et al. Explorative Analysis of Low-Dose Metronomic Chemotherapy with Cyclophosphamide and Methotrexate in a Cohort of Metastatic Breast Cancer Patients. Breast Care (Basel) 2018; 13: 272-276

[14] Langkjer ST, Kenholm J, Jensen JD et al. The NAME trial: a direct comparison of classical oral Navelbine versus Metronomic Navelbine in metastatic breast cancer. Future Oncol 2019; 15: 2561-2569

[15] Maur M, Omarini C, Piacentini F et al. Metronomic Capecitabine Effectively Blocks Leptomeningeal Carcinomatosis From Breast Cancer: A Case Report and Literature Review. Am J Case Rep 2017; 18: 208-211

[16] Montagna E, Bagnardi V, Cancello G et al. Metronomic Chemotherapy for First-Line Treatment of Metastatic Triple-Negative Breast Cancer: A Phase II Trial. Breast Care (Basel) 2018;13: 177-181

[17] Masci G, Losurdo A, Gandini C et al. Low-dose "metronomic chemotherapy" with oral cyclophosphamide and methotrexate in metastatic breast cancer: a case report of extraordinarily prolonged clinical benefit. Ecancermedicalscience 2012; 6: 275
[18] Gray R, Bhattacharya S, Bowden C et al. Independent Review of E2100: A Phase III Trial of Bevacizumab Plus Paclitaxel Versus Paclitaxel in Women With Metastatic Breast Cancer. J Clin Oncol 2009; 27: 4966-4972

[19] Miller K, Wang M, Gralow J et al. Paclitaxel plus Bevacizumab versus Paclitaxel Alone for Metastatic Breast Cancer. N Engl J Med 2007; 357: 2666-2676

[20] Robert N], Diéras V, Glaspy J et al. RIBBON-1: Randomized, DoubleBlind, Placebo-Controlled, Phase III Trial of Chemotherapy With or Without Bevacizumab for First-Line Treatment of Human Epidermal Growth Factor Receptor 2-negative, Locally Recurrent or Metastatic Breast Cancer. J Clin Oncol 2011; 29: 1252-1260

[21] Im SA, Lu Y-S, Bardia AB et al. Overall Survival with Ribociclib plus Endocrine Therapy in Breast Cancer. N Engl J Med 2019; 381: 307-316

[22] Slamon D, Neven P, Chia $S$ et al. Overall survival results of the Phase III MONALEESA-3 trial of postmenopausal patients with hormone receptor-positive human-epidermal growth factor-2-negative advanced breast cancer treated with fulvestrant plus/minus ribociclib. Ann Oncol 2019; 30 (Suppl. 5): v851-v934

[23] Online: www.esmo.org/guidlines/esmo-mcbs; last access: 30.11.2019

[24] Cherny NI, Sullivan R, Dafni U et al. A standardised, generic, validated approach to stratify the magnitude of clinical benefit that can be anticipated from anti-cancer therapies: the European Society for Medical Oncology Magnitude of Clinical Benefit Scale. Ann Oncol 2015; 26: 15471573

[25] Cherny NI, Dafni U, Bogaerts ] et al. ESMO Magnitude of Clinical Benefit Scale version 1.1. Ann Oncol 2017; 28: 2340-2366

[26] Hartkopf AD, Huober J, Volz B et al. Treatment landscape of advanced breast cancer patients with hormone receptor positive HER2 negative tumors - Data from the German PRAEGNANT breast cancer registry. Breast 2018; 37: 42-51

[27] Endocrine Therapy Plus CDK4/6 in First or Second Line for Hormone (SONIA) Receptor Positive Advanced Breast Cancer Online: https:// clinicaltrials.gov/ct2/show/study/NCT03425838; last access: 02.05.2020

[28] André F, Ciruelos E, Rubovszky G et al. Alpelisib for PIK3CA-mutated, hormone receptor-positive advanced breast cancer. N Engl ] Med 2019; 380: $1929-1940$

[29] Park YH, Kim TY, Kim GM et al. A randomized phase Il study of palbociclib plus exemestane with GNRH agonist versus capecitabine in premenopausal women with hormone receptor-positive metastatic breast cancer (KCSG-BR 15-10, NCT02592746). J Clin Oncol 2019; 37 (Suppl.): Abstr. 1007

[30] Martín M, Zielinski C, Ruíz-Borrego M et al. Results from PEARL study (GEICAM/2013-02_CECOG/BC.1.3.006): A phase 3 trial of Palbociclib (PAL) in combination with endocrine therapy (ET) versus Capecitabine (CAPE) in hormonal receptor (HR)-positive/human epidermal growth factor receptor (HER) 2-negative metastatic breast cancer (MBC) patients (pts) whose disease progressed on aromatase inhibitors (Als). San Antonio Breast Cancer Symposium 2019; GS2-07

[31] Mehta RS, Barlow WE, Albain KS et al. Overall Survival with Fulvestrant plus Anastrozole in Metastatic Breast Cancer. N Engl J Med 2019; 380: 1226-1234

[32] Bergh J, Jönsson PE, Lidbrink EK et al. FACT: an open-label randomized phase III study of fulvestrant and anastrozole in combination compared with anastrozole alone as first-line therapy for patients with receptorpositive postmenopausal breast cancer. J Clin Oncol 2012; 30: 19191925

[33] Johnston SR, Kilburn LS, Ellis P et al.; SoFEA investigators. Fulvestrant plus anastrozole or placebo versus exemestane alone after progression on non-steroidal aromatase inhibitors in postmenopausal patients with hormone-receptor-positive locally advanced or metastatic breast cancer (SoFEA): a composite, multicentre, phase 3 randomised trial. Lancet Oncol 2013; 14: 989-998 
[34] Saura C, Oliveira M, Feng YH. Neratinib + capecitabine vs. lapatinib + capecitabine in patients with HER2+ metastatic breast cancer previously treated with $\geq 2$ HER2-directed regimens: Findings from the multinational, randomized, phase III NALA trial. JCO ASCO Ann Meeting 2019; \#1002

[35] Pivot X, Manikhas A, Zurawski B et al. CEREBEL (EGF111438): A Phase III, Randomized, Open-Label Study of Lapatinib Plus Capecitabine Versus Trastuzumab Plus Capecitabine in Patients With Human Epidermal Growth Factor Receptor 2-Positive Metastatic Breast Cancer. J Clin Oncol 2015; 33: 1564-1573

[36] Schmid P, Adams S, Rugo H et al. Atezolizumab and nab-Paclitaxel in Advanced Triple-Negative Breast Cancer. N Engl J Med 2019; 379: 21082121

[37] Cortes ], Lipatov O, Im S et al. KEYNOTE-119: Phase 3 study of pembrolizumab versus single-agent chemotherapy for metastatic triple-negative breast cancer. Ann Oncol 2019; 30 (Suppl. 5): v85-v934

[38] Online: www.gbg.de/de/studien/brainmet.php; last access: 15.12.2019

[39] Robson M, Im SA, Senkus E et al. Olaparib for Metastatic Breast Cancer in Patients with a Germline BRCA Mutation. N Engl J Med 2017; 377: 523533

[40] Robson ME, Tung N, Conte P et al. OlympiAD final overall survival and tolerability results: Olaparib versus chemotherapy treatment of physician's choice in patients with a germline BRCA mutation and HER2-negative metastatic breast cancer. Ann Oncol 2019; 30: 558-566

[41] Litton JK, Rugo HS, Ettl J et al. Talazoparib in Patients with Advanced Breast Cancer and a Germline BRCA Mutation. N Engl J Med 2018; 379: 753-763
[42] Lux M, Lewis K, Rider A et al. BRCA1/2 Testing in HER2- Advanced Breast Cancer (ABC): Results from the European Component of a Multi-Country Real World Study. Ann Oncol 2019; 30 (Suppl. 5): v99-v103. doi:10.1093/annonc/mdz241 (Poster ESMO 2019)

[43] Dieras VC, Han HS, Kaufman B et al. Phase 3 study of veliparib with carboplatin and paclitaxel in HER2-negative advanced/metastatic gBRCAassociated breast cancer. Ann Oncol 2019; 30 (Suppl. 5): v851-v934

[44] ESMO Clinical Practice Guidelines: Supportive and Palliative Care Online: https://www.esmo.org/guidelines/Supportive-and-Palliative-Care; last access: 30.11 .2019

[45] Hortobagyi GN, Van Poznak C, Harker WG et al. Continued Treatment Effect of Zoledronic Acid Dosing Every 12 vs. 4 Weeks in Women With Breast Cancer Metastatic to Bone: The OPTIMIZE-2 Randomized Clinical Trial. JAMA Oncol 2017; 3: 906-912

[46] Awan AA, Hutton B, Hilton J et al. De-escalation of bone-modifying agents in patients with bone metastases from breast cancer: a systematic review and meta-analysis. Breast Cancer Res Treat 2019; 176: 507517

[47] Online: www.awmf.org; last access: 30.11.2019. Additionally: S3 Guideline "Early Detection, Diagnostics, Therapy and Follow-up Care in Breast Cancer." Long Version 4.0. - December 2017. AWMF Registry No. 032045OL. Online: www.leitlinienprogramm-onkologie.de; last access: 30.11.2019

[48] Expanded S3 Guideline on palliative care for patients with incurable cancer. Long Version 2.0 - August 2019. AWMF Registry number: 128/001OL. Online: https://www.dgpalliativmedizin.de/neuigkeiten/august2019-erweiterte-s3-leitlinie-palliativmedizin.html; last access: 20.01.2020

[49] Dykewicz CA. Summary of the guidelines for preventing opportunistic infections among hematopoietic stem cell transplant recipients. Clin Infect Dis 2001; 33: 139-144 